\title{
Sensitivity of the regional European boreal climate to changes in surface properties resulting from structural vegetation perturbations
}

\author{
J. H. Rydsaa, F. Stordal, and L. M. Tallaksen \\ Department of Geosciences, University of Oslo, Oslo, Norway \\ Correspondence to: J. H. Rydsaa (j.h.rydsaa@geo.uio.no) \\ Received: 23 September 2014 - Published in Biogeosciences Discuss.: 7 November 2014 \\ Revised: 13 March 2015 - Accepted: 18 April 2015 - Published: 27 May 2015
}

\begin{abstract}
Amplified warming at high latitudes over the past few decades has led to changes in the boreal and Arctic climate system such as structural changes in high-latitude ecosystems and soil moisture properties. These changes trigger land-atmosphere feedbacks through altered energy partitioning in response to changes in albedo and surface water fluxes. Local-scale changes in the Arctic and boreal zones may propagate to affect large-scale climatic features. In this study, MODIS land surface data are used with the Weather Research and Forecasting model (WRF V3.5.1) and Noah land surface model (LSM), in a series of experiments to investigate the sensitivity of the overlying atmosphere to perturbations in the structural vegetation in the northern European boreal ecosystem. Emphasis is placed on surface energy partitioning and near-surface atmospheric variables, and their response to observed and anticipated land cover changes. We find that perturbations simulating northward migration of evergreen needleleaf forest into tundra regions cause an increase in latent rather than sensible heat fluxes during the summer season. Shrub expansion in tundra areas has only small effects on surface fluxes. Perturbations simulating the northward migration of mixed forest across the present southern border of the boreal forest, have largely opposite effects on the summer latent heat flux, i.e., they lead to a decrease and act to moderate the overall mean regional effects of structural vegetation changes on the near-surface atmosphere.
\end{abstract}

\section{Introduction}

Amplified warming at high latitudes over the past few decades has led to changes in the boreal and Arctic climate system such as structural changes in high-latitude ecosystems (Chapin et al., 2010; Serreze and Barry, 2011). This polar amplification of global warming is in part due to a cascade of local feedback mechanisms that act to increase the initial greenhouse gas forcing (Overpeck et al., 1997; Serreze and Barry, 2011). Extensive evidence gathered over the past few decades, has established the fact that changes in high-latitude ecosystems are part of these mechanisms, through the redistribution of physical surface properties controlling processes that act to amplify or reduce initial warming (Beringer et al., 2001; Sturm et al., 2001; Chapin et al., 2005; Bonan, 2008). Important mechanisms include changes in surface energy and water flux partitioning, which could affect regional or continental-scale evapotranspiration-precipitation feedbacks (Eugster et al., 2000; Thompson et al., 2004; Beringer et al., 2005), and surface albedo (e.g., Betts and Ball, 1997; Chapin et al., 2005; Serreze and Barry, 2011). Physical changes may have the largest direct impacts on the local scale. However, local-scale feedbacks may propagate to regional and continental scales through cross-scale links, and possibly lead to critical transitions in the large-scale climate (Rietkerk et al., 2011). Bonan (2008) suggests that the boreal forest might, through its control on high-latitude surface albedo, especially during winter, have the highest biophysical effect of all biomes on the mean global temperature. Additionally, by investigating the climate benefits of afforestation mitigation strategies, Arora and Montenegro (2011) found that in high latitudes, the warming effect of decreased surface albedo re- 
lated to increased forest cover dominated the cooling effect of increased carbon sequestration, supporting similar findings of Betts et al. (2007).

Several global vegetation modeling studies have predicted potential vegetation changes in response to future warming and elevated $\mathrm{CO}_{2}$ concentrations (e.g., Lucht et al., 2006; Alo and Wang, 2008; Sitch et al., 2008; Strengers et al., 2010; Jeong et al., 2011; Jeong et al., 2014). Common features in these studies include the migration of boreal forest towards higher latitudes and altitudes (i.e., northward expansion of trees and shrubs into tundra ecosystems) and the replacement of boreal forest by more temperate vegetation species along the southern edges of the boreal zone. Soja et al. (2007) concluded that substantial observational evidence across the circumpolar boreal region over the past several decades indicates that the biosphere in the region has already responded to climate changes in accordance with modeled predictions. They found upper and lower tree lines in mountainous regions across Siberia to have altered in response to a warmer climate, as predicted by global dynamic vegetation models (e.g., Jeong et al., 2011, 2014). In addition, observed changes to vegetation include increased biomass production in highlatitude ecosystems as a response to higher temperatures and longer growing season.

Several studies based on remote sensing have confirmed increased photosynthetic activity related to increased plant growth and increased growing seasons over the past few decades (Myneni et al., 1997; Bhatt et al., 2010; Piao et al., 2011). Bhatt et al. (2010) link increased high-latitude ecosystem productivity to a decrease in near-coastal sea ice and summer tundra surface temperatures, supporting the findings of Jeong et al. (2014), who conclude that vegetationatmosphere-sea ice interaction gives rise to additional positive feedback of the Arctic amplification, based on a series of coupled vegetation-climate model simulations under a doubled $\mathrm{CO}_{2}$ environment. In addition, the northward expansion of boreal and Arctic vegetation into previously tundracovered regions, also referred to as the Arctic greening, is a widely observed feature across the Arctic region. Chapin et al. (2005) calculated that $2.3 \%$ of the treeless area in northern Alaska has been converted to forest from tundra over the past 50 years, corresponding to an area of $11600 \mathrm{~km}^{2}$. They highlight the importance of this redistribution in vegetation on surface albedo and temperatures. By analyzing a wide range of independent sets of measurement data, they found that the changes in terrestrial summer albedo enhances the high-latitude warming which is increasing atmospheric heating locally by as much as $3 \mathrm{Wm}^{-2}$ per decade, comparable to the regional effects expected over multiple decades as result of atmospheric $\mathrm{CO}_{2}$ doubling. Although the heating signal is mainly due to a prolonged snow free season, they expect that the expansion of shrubs and trees into the former tundra zones is likely to contribute to enhance summer warming in the future. Xu et al. (2013) found that a decrease of highlatitude temperature seasonality equivalent to a climatic $4^{\circ}$ latitudinal shift equatorward, has been observed in the Arctic region over the past 30 years. They estimate that a further diminishment in temperature seasonality equivalent to a full $20^{\circ}$ latitudinal southward shift could occur within this century.

However, not all boreal and Arctic sites respond to increased temperatures with an increased biomass production. A second type of response to warming is a reduction in photosynthetic activity, referred to as browning. Lloyd and Bunn (2007) observed that while most high-latitude ecosystems have shown a positive trend in seasonal photosynthetic activity over the past few decades, some boreal ecosystems, mostly in the continental interior, showed significant downward trends in photosynthetic activity as response to increased temperatures, especially in the last 2 decades. They explain this as a result of temperature stress, or temperatureinduced moisture stress, related to increased rates of evapotranspiration.

Changes in surface vegetation properties have a direct effect on the surface fluxes of latent and sensible heat. The ratio between the two, the Bowen ratio (sensible to latent heat flux), is an important climatic measure and highly sensitive to surface physical properties (Baldocchi et al., 2000; Wilson et al., 2002). For instance, based on an analysis of available data on surface energy balance of the Arctic and boreal ecosystems, Eugster et al. (2000) found that in general evergreen conifer forests have a canopy conductance half of that of deciduous forests, resulting in a higher sensible heat flux, and lower latent heat flux over evergreen conifer forests. They estimate a reduction in Bowen ratio in areas where warming-induced shifts from conifer forest to deciduous forest occur. Arctic ecosystems, like light taiga and tundra ecosystems, have a higher ground heat flux due to less shade from canopies compared to forested sites (Yang et al., 1999). Thompson et al. (2004) conclude that the heating associated with more complex canopies may influence regional feedback processes by increasing boundary layer height through increased sensible heat flux. These findings were supported by Beringer et al. (2005), who measured warmer and drier fluxes moving along the transition zone from Arctic tundra to boreal forest. They found a relative increase in sensible heat flux resulting in an increase in Bowen ratio from 0.94 to 1.22 going from tundra to forested sites. They also argue that shifting the vegetation type towards one with a higher leaf area index (LAI) values may cause a shift in the relationship between latent heat flux and the state of the overlying atmosphere and mesoscale weather systems through the link between transpiration and the vapor pressure deficit in the surrounding air. Shifting the vegetation type was found to have a less of an impact on the dependence on soil water content due to the low correlation to latent heat flux at all sites.

Changing vegetation and surface properties will, through its control on surface fluxes of heat and moisture, influence the planetary boundary layer and general circulation patterns 
(Pielke and Vidale, 1995; Beringer et al., 2001; Liess et al., 2011). Recently, Liess et al. (2011) modeled whether or not changing vegetation cover in the Arctic zone could influence even mesoscale circulation patterns. They simulated the effects of a moderate northward forest replacement of shrub ecosystems along the southern tundra circumpolar border zone on the summertime polar front. They estimated a regional broadening and strengthening of the polar jet stream of up to $3 \mathrm{~m} \mathrm{~s}^{-1}$, and concluded that the effects of the regional forest expansion could reach even the stratospheric circulation.

Uncertainties within vegetation-climate modeling are large, especially with regard to future species redistribution and climate feedback (e.g., Friedlingstein et al., 2013). Investigating the response of the overlying atmosphere to specific structural changes in vegetation may yield valuable information that might reduce uncertainties with regard to climate response to the complex present and future changes in boreal ecosystems. Limiting the uncertainties related to modeled potential vegetation changes, Snyder and Liess (2014) instead applied a one-grid-cell northward shift in boreal vegetation in a global climate model to explore the response of the overlying atmosphere to a vegetation shift expected to occur within a century. This shift gave an annual warming of $0.3^{\circ} \mathrm{C}$ mainly due to decreased surface albedo.

Changes in migration speed in response to climatic changes vary greatly across species types. As ecosystems consist of complex, co-dependent compositions of wide ranges of species, the total ecosystem migration speed will be equally complex. However, cross-species observational studies confirm a general northward and altitudinal shift in the boreal area, a trend matching climate change predictions (Parmesan and Yohe, 2003; Chen et al., 2011). On a global scale, Chen et al. (2011) derived a median cross species migration rate of $16.9 \mathrm{~km}$ per decade, nearly doubling the estimate of Parmesan and Yohe (2003), who derived an average range shift of $6.1 \mathrm{~km}$ per decade in their meta-analyses based on some 1700 species across the globe. These average rates of migration estimates are often seen in contrast to those of dynamic vegetation models, which often assume strict relationships between species redistribution and altered climatic environment, yielding sometimes abrupt changes in species composition in large areas over short timespans. Many of these models simulate vegetation response to climate change based on accumulated values such as growing degree days and accumulated precipitation values, forcing the vegetation to keep within their respective climate envelopes. In cases of rapid climatic changes, the vegetation may therefore move unrealistically fast into new areas, often within the timespan of a century. To assess two extreme scenarios, in which species follow their climatic environment completely, or do not move out of their current habitats at all in spite of changing climatic conditions, Mckenney et al. (2007) investigated potential migration scenarios of 130 North American tree species, based on future climate predictions. They found that on average, a northward distribution shift of between 330 and $700 \mathrm{~km}$ depending on the species' ability to migrate at the same rate as their current climatic conditions was likely to occur by the end of this century, along with large decreases in future potential habitats.

In this study, we investigate the sensitivity of altered land cover properties on fine-resolution surface fluxes and regional-scale atmospheric response mechanisms by conducting two experiments with manually altered structural vegetation distribution. These experiments represent two potential future boreal and Arctic ecosystem changes, and are compared to a control run present-day state of vegetation distribution. An invariant vegetation distribution in each simulation is used to isolate effects of changes in land surface properties related to structural vegetation changes on the regional climate. Meteorological forcing data in both simulations matches that of the control run to further isolate the long-term effects of vegetation changes on the overlying atmosphere.

\section{Model and methodology}

The Weather Research and Forecasting model (WRF V3.5.1) is a non-hydrostatic, mesoscale weather prediction system (Skamarock and Klemp, 2008). It is a model with a wide variety of applications across scales ranging from large eddies to global simulations. Simulation timescales vary between short-term case studies of a few hours or less, to regional climate studies spanning decades. In this study, WRF has been run with the Noah land surface model (LSM) (Tewari et al., 2004), which is a well-tested model widely used in the modeling community. In Noah, the ground surface consists of four soil layers that are 10, 30, 60 and $100 \mathrm{~cm}$ thick, adding up to a total soil depth of $2 \mathrm{~m}$. The top layer is a combined vegetation, snow and soil layer, and surface properties are dependent on soil and vegetation category. Each vegetation category is assigned range values for parameters related to the vegetation's influence on the land-atmosphere interaction such as the albedo, roughness length, stomatal resistance (Rs) and LAI value. The vegetation properties are further dependent on the greenness vegetation fraction, describing the vegetation density in each grid cell. The LSM controls the surface and soil water budget and computes surface water and energy fluxes from the surface to the atmosphere. The turbulent fluxes are influenced by vegetation properties such as stomatal resistance, LAI value and surface roughness length, in addition to the wind speed. The model is run at a spatial resolution of $27 \mathrm{~km}$ with 52 vertical layers. The time resolution is $2 \mathrm{~min}$, and output is written every $3 \mathrm{~h}$. The model setup is further presented in Table 1. The choice of model configuration is based in part on sensitivity testing of various schemes (not shown), and in part out of considerations of available output variables of different parameterizations. A review of literature with regard to choices best 
Table 1. Key parameterizations chosen for the model setup.

\begin{tabular}{ll}
\hline Parameterization scheme & Reference \\
\hline Mellor-Yamada-Janjić planetary boundary layer & Janjić (1994) \\
Morrison two moment microphysics & Morrison et al. (2009) \\
RRTMG short- and longwave radiation options & Iacono et al. (2008) \\
Kain-Fritsch cumulus scheme & Kain (2004) \\
\hline
\end{tabular}

suited for a cold region intermediate-resolution simulation, and a consideration of the NCAR cold-climate intermediateresolution example setup (Skamarock et al., 2008) and the Polar WRF setup (Hines et al., 2011), also contributed to the current model configuration.

For the initial and boundary conditions, we use the ERA Interim 6-hourly reanalysis. Boundary conditions for the years 2000-2010 are used for the simulations, where the first year is regarded a spin-up year and not included in the analyses. The same boundary conditions are applied in all three simulations to isolate the effect of structural vegetation changes on the overlying atmosphere and climate. The 10year simulation length was chosen in order to achieve a good estimate of the mean responses of the overlying atmosphere to vegetation changes without interannual variation influencing the results. Although even longer simulations might be advantageous, 10 years was chosen as a compromise between length and computational cost while maintaining high temporal and spatial resolutions in the simulations. The time period chosen for meteorological forcing (2001-2010) is coherent with the selected set of vegetation data and acts as a suitable reference period for present-day conditions. As the meteorological conditions are only altered as response to the vegetation shifts inside the modeled domain, the simulation setup is not able to estimate downstream effects of vegetation perturbations.

For land use data, the MODIS IGBP modified 21 class land surface data is used. This data set is available with the standard WRF package download. The data set is based on the original $1 \mathrm{~km}$ resolution MODIS IGBP vegetation map (Friedl et al., 2010), but excludes permanent wetland and has three tundra classes and lakes added by the Land Team at EMC/NCEP. To represent high-latitude and high-altitude ecosystems more accurately, the vegetation category of open shrub land has been replaced by various tundra vegetation classes north of $60^{\circ} \mathrm{N}$ in the modified MODIS data set. This replacement results in an artificial shift in vegetation that can be detected along this latitude across a mountain plateau in southern Norway. In this study, the remaining grid cells of shrub land south of $60^{\circ} \mathrm{N}$ and west of $15^{\circ} \mathrm{E}$, are adjusted into wooded tundra below, and mixed tundra above the height of the local tree line to achieve a vegetation distribution more consistent with local ecosystems in this area. This adjustment affects in total 12 grid cells representing $8748 \mathrm{~km}^{2}$. In the rest of the domain, the vegetation shift along the $60^{\circ} \mathrm{N}$ has no abrupt shifts or other negative implications for the pur-

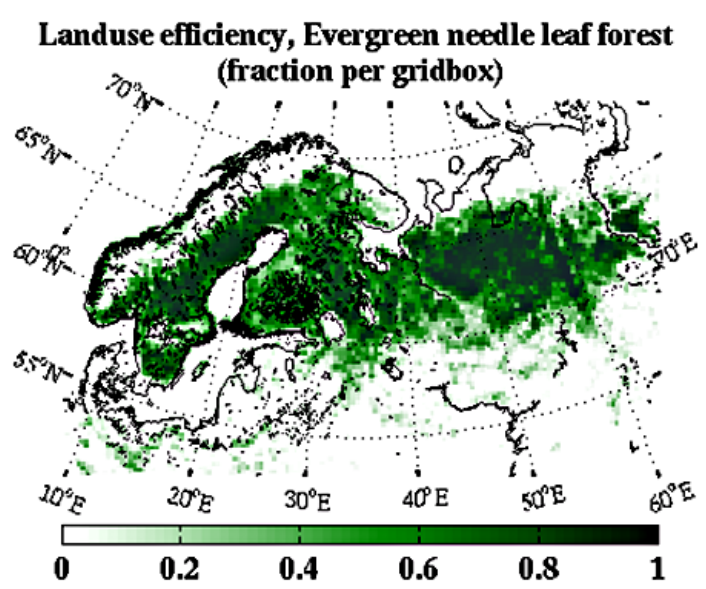

Figure 1. The northern European boreal forest domain, represented here by evergreen needleleaf forest as fraction of grid cell, remapped from the modified IGBP MODIS data to $27 \times 27 \mathrm{~km}$ resolution.

pose of this study. The study area, which covers the northern European boreal zone, is shown in Fig. 1, represented by evergreen needleleaf forest as this is the dominant vegetation type in this area.

\subsection{Experiments}

The goal of the experimental setup is to investigate the sensitivity of the land-atmosphere interactions to changes in vegetation distribution. Perturbations to the land cover are used to represent a northward migration of boreal ecosystems based on the aforementioned observed and anticipated features in vegetation migration patterns. Experiments are designed to induce atmospheric response and feedback mechanisms while keeping perturbation complexity low enough to be able to identify the respective response mechanisms related to each of the applied vegetation shifts. The aim is to induce moderate and realistic scale changes, representative of actual vegetation shifts on a century-long timescale.

We isolate the effects of specific vegetation changes by applying simplified perturbations to the dominant vegetation categories as given by the selected set of land use data. The perturbations each represent a given trend of forest migration in this area. As such, the perturbations are not to be regarded as estimates of a future state of vegetation distribution in the area under a specific climate scenario, but rather adjustments based on observed and anticipated trends applied for the purpose of this sensitivity study. No assumptions are made with regard to changes in vegetation density after redistribution. A 10-year simulation period is used, and averages over this period are regarded as a good indicator of climate response to the perturbations. Assuming vegetation changes induced by a changing climate, this experimental setup is not relevant for an unlimited timespan; rather, it reflects moderate changes in simulated vegetation shifts. Keeping in line 
Table 2. Key parameters for the dominant vegetation categories used in Experiment 1 and Experiment 2 (Ex 1 and Ex 2).

\begin{tabular}{lrrrrrrr}
\hline Vegetation category & $\begin{array}{r}\text { Min } \\
\text { LAI }\end{array}$ & $\begin{array}{r}\text { Max } \\
\text { LAI }\end{array}$ & $\begin{array}{r}\text { Roughness } \\
\text { length }\end{array}$ & $\begin{array}{r}\text { Min } \\
\text { albedo }\end{array}$ & $\begin{array}{r}\text { Max } \\
\text { albedo }\end{array}$ & Rs & $\begin{array}{r}\text { Max snow } \\
\text { albedo }\end{array}$ \\
\hline Mixed tundra & 0.41 & 3.35 & 0.15 & 0.15 & 0.2 & 150 & 60 \\
Wooded tundra & 0.41 & 3.35 & 0.3 & 0.15 & 0.2 & 150 & 55 \\
Evergreen needleleaf forest & 5 & 6.4 & 0.5 & 0.12 & 0.12 & 125 & 52 \\
Mixed forest & 2.8 & 5.5 & 0.5 & 0.17 & 0.25 & 125 & 53 \\
\hline
\end{tabular}

with the meta-analyses of migration speeds across species and assuming a time horizon on the scale of about a century, an upper limit of a moderate $100 \mathrm{~km}$ vegetation migration is applied to vegetation redistribution. Perturbations related to vegetation shifts only imply changes in the biophysical properties of the surface, while biochemical, atmospheric and hydrological properties are not perturbed. The only difference between the simulations is the described changes in vegetation distribution and resulting feedback effects of these, as simulations are in all other aspects identical. As the vegetation cover is not able to react to meteorological forcing during the simulations (non-dynamical vegetation), the effects of the structural vegetation perturbations are one-way in this study; therefore, all changes in the meteorological conditions as compared to the control simulation may be assumed a result of vegetation perturbations alone. The applied changes in dominant vegetation category for each experiment, as compared to the control simulation, are illustrated in Fig. 2.

\subsubsection{Experiment 1}

The main emphasis in the first experiment (hereafter Ex 1) is on the widely documented feature of Arctic shrub expansion into tundra regions. This change involves an increase in surface roughness and wintertime albedo, as documented by, for example, Chapin et al. (2005). This is also regarded as the most rapid of the applied vegetation shifts, and as such occupies the largest area of applied changes. To represent this vegetation shift, a moderate change in tundra vegetation is applied by changing the areas covered by the vegetation category of "mixed tundra" into "wooded tundra", thereby slightly increasing the roughness length, and reducing the wintertime albedo (Table 2). In addition, to account for another important trend in the northernmost latitudes of our domain, we have made a perturbation representing the northward migration of the boreal forest by applying the land use category of evergreen needleleaf forest in areas previously covered by wooded tundra. The shift is applied up to $108 \mathrm{~km}$ to represent a slow migration towards higher latitudes in areas that are already covered by vegetation. This northward shift of dense forest implies an increase in LAI and decrease in albedo owing to the denser canopy of the evergreen forest (Table 2). For Ex 1, these two vegetation changes imply changes of a total area of $563517 \mathrm{~km}^{2}$ of shrub expan- sion/tundra conversion and a minor area of $181521 \mathrm{~km}^{2}$ of northward migrating evergreen forest (Fig. 2, left panel).

\subsubsection{Experiment 2}

In the second experiment (hereafter Ex 2), the northward migration of the southern edges of boreal forest is also taken into account by applying a perturbation representing a northward migration of the southern border of the evergreen forest and its replacement with more temperate species. To achieve this, in addition to the changes made for Ex 1, the southern border of the evergreen needleleaf forest is shifted northward by up to $108 \mathrm{~km}$ (similar to the migration of evergreen forest on the northern border), replaced by the category of mixed forest, representing a slow transition towards a more temperate forest type. For the physical properties of the surface, this implies a decrease in maximum and minimum LAI values and increase in maximum and minimum albedo (Table 2). These vegetation changes cover a total area of $392202 \mathrm{~km}^{2}$ of northward migrating mixed forest, and represents as such a substantial shift in vegetation, although consistent with the northern vegetation perturbations in Ex 1.

\section{Results}

Results are largely presented as differences between experimental simulations as compared to the control run. To account for inter-seasonal and interannual variations, we start by examining the long-term average effects across the full length of the 10-year simulation period (excluding the spinup year), largely focusing on regional means. Time averages are all based on the $3 \mathrm{~h}$ output frequency, and as such, represents mean day and night values. In addition, average changes over selected areas of specified vegetation shifts are presented to highlight the effects of individual vegetation changes. The main emphasis is on alterations in surface fluxes and near-surface atmosphere; however, a short investigation of effects on soil moisture content is also conducted. We investigate the seasonal variations in Sect. 3.2 and try to further isolate conditional effects with regard to water deficits in soil and air in Sect. 3.3. 

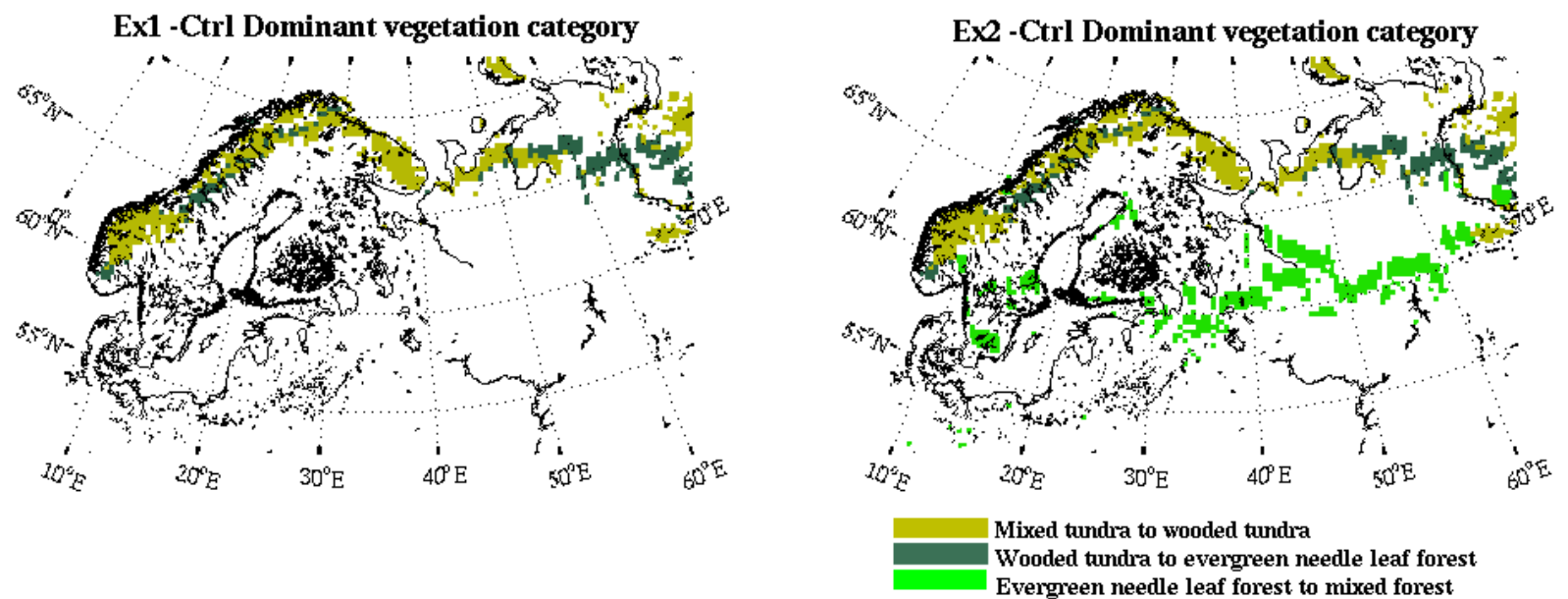

Figure 2. Changes in dominant vegetation category as compared to the control simulation for Ex 1 (left panel) and Ex 2 (right panel). The olive-green color represents areas where the dominant category is changed from mixed tundra to wooded tundra to represent shrub expansion. Dark green indicates areas where the dominant land use category of wooded tundra has been replaced by evergreen needleleaf forest. Light green represents areas where mixed forest has taken over evergreen needleleaf forest (only Ex 2).
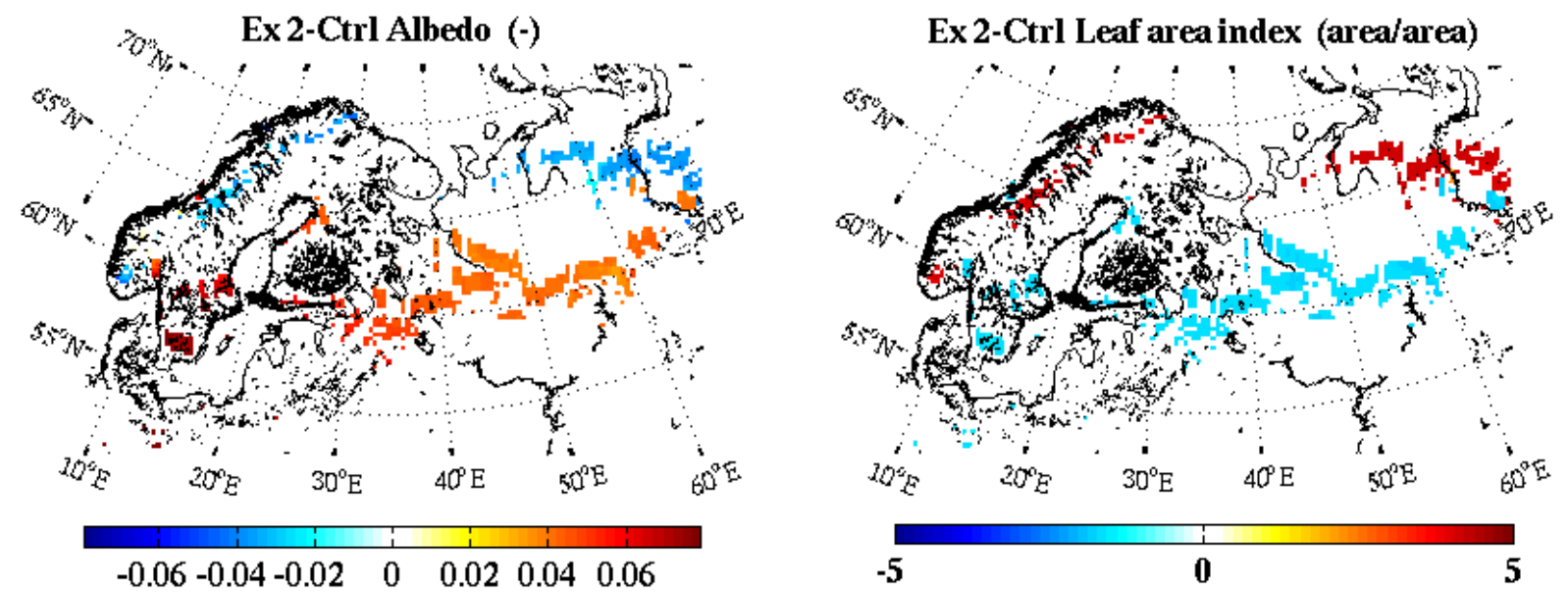

Figure 3. Changes in 10-year average albedo (left panel) and LAI (right panel) for Ex 2 (including all vegetation changes), as compared to the control simulation.

\subsection{0-year averages: what are the overall effects of vegetation changes?}

The applied vegetation changes lead to alterations in key surface parameters such as surface albedo and LAI, corresponding to their new minimum and maximum values assigned to each vegetation category in the model parameterization (Table 2). The 10-year average change in albedo due to structural vegetation changes is shown in Fig. 3. Here the difference between Ex 2 and the control run is shown to account for all applied vegetation changes. The effect on albedo and LAI changes is not constant throughout the year (Sect. 3.2) and across the domain, and is a result of the scaling between vegetation dependent prescribed minimum and maximum values using the vegetation greenness fraction throughout the year.
The annual average features represented here show that in areas with a northward migrating evergreen needleleaf forest, vegetation changes largely leads to a decrease in surface albedo, whereas areas with simulated shrub expansion do not affect the 10-year average albedo notably. The southern border change from evergreen needleleaf to mixed forest leads to a year-round increase in surface albedo. A general increase in LAI is seen in areas with a northward-expanding evergreen needleleaf forest, whereas a decrease is seen across the area of mixed forest migration (Fig. 3, right panel). The areas of shrub expansion do not influence the LAI. The changes in these surface properties together with the roughness length are largely what induce the changes in the land-atmosphere interactions described below. 

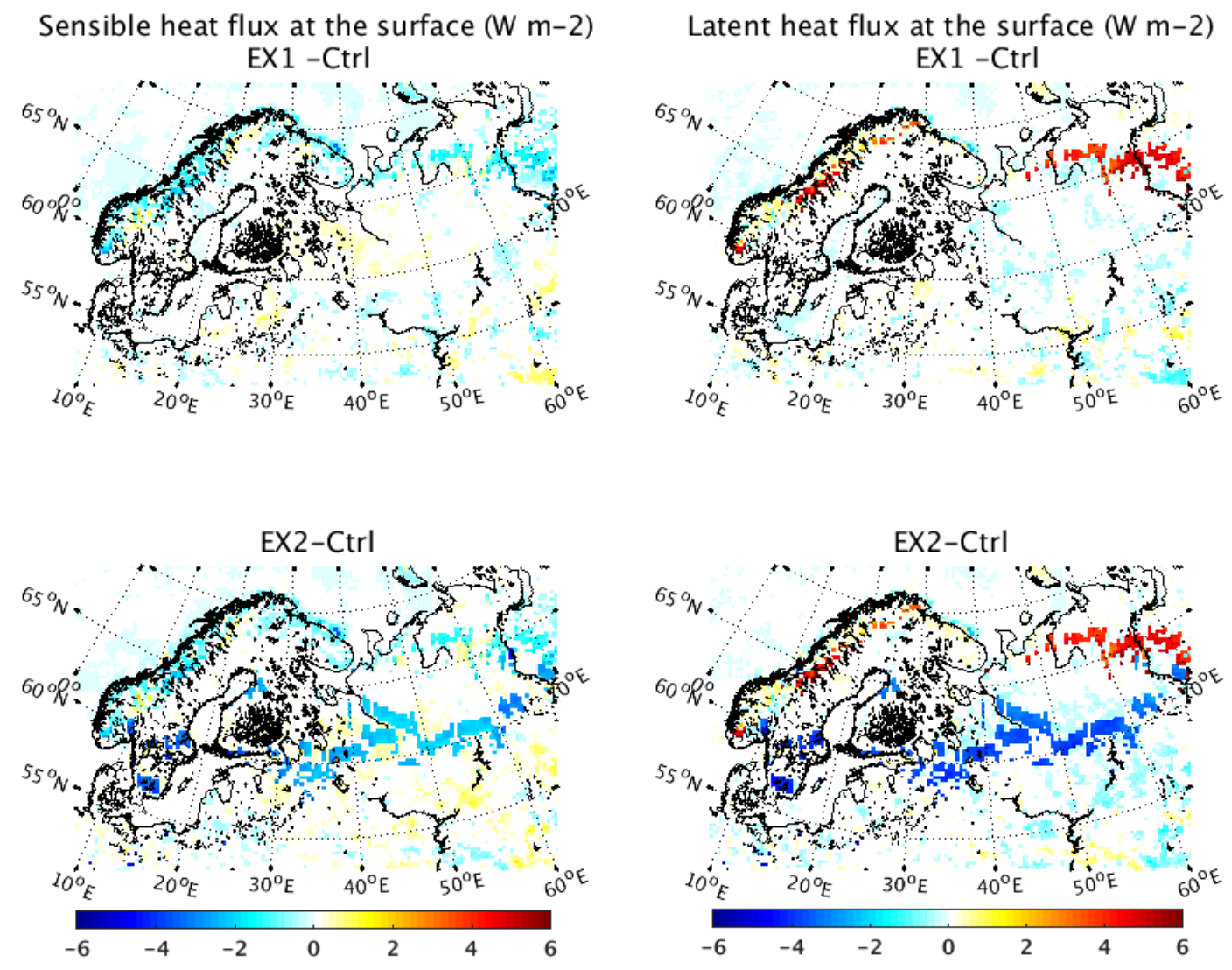

Figure 4. Changes in 10-year average surface sensible heat flux (left panels) and latent heat flux (right panels), as compared to the control simulation. Ex 1 in upper panels, Ex 2 in lower panels (only showing significant results at the $95 \%$ confidence level).

The 10-year average changes in sensible and latent surface fluxes as compared to the control simulation are presented in Fig. 4 for both experiments. Only statistically significant results at the $95 \%$ confidence level based on Student's $t$ test are presented. The overall average effect of vegetation changes is a decrease in sensible heat flux to the atmosphere (left panels). Shrub expansion has only a minor influence on the average sensible heat flux. As seen in the lower left panel, the most pronounced negative effect is a result of the northward advancement of mixed forest (Ex 2). The northernmost expansion of evergreen trees into tundra also reduces the sensible heat flux, but not to the same degree. There are large seasonal variations in the sensible heat response, and these results largely reflect the summer season results (see Sect. 3.2). The reduction in sensible heat flux over the entire 10-year period for Ex 1 compared to the control run is $0.7 \mathrm{~W} \mathrm{~m}^{-2}$ for areas averaged over both shrub expansion and northward migrating evergreen forest (all numbers refer to averages in areas with vegetation changes only). The corresponding number for Ex 2, considering all vegetation changes, is a reduction of $1.4 \mathrm{~W} \mathrm{~m}^{-2}$, mostly a response to the mixed forest northward migration (Fig. 7).

A contrasting pattern is seen in the effect on the latent heat flux (Fig. 4, right panel). The northward migrating forest and shrub expansion in Ex 1 both enhance the latent heat flux, with areas experiencing a northward migrating evergreen needleleaf forest, dominating the results (upper panels). The 10 -year average response in Ex 1 is an increase in the latent heat flux by $1.2 \mathrm{~W} \mathrm{~m}^{-2}$. This number also includes areas with tundra shrub expansion, and the mean change over areas with northward-expanding evergreen forest only is $4.4 \mathrm{~W} \mathrm{~m}^{-2}$. In Ex 2, the mean effect of vegetation migration is a reduction of the latent heat flux by $0.4 \mathrm{~W} \mathrm{~m}^{-2}$, mainly influenced by the negative effect of the mixed forest expansion, in which areas the average latent heat flux is reduced by $3.5 \mathrm{~W} \mathrm{~m}^{-2}$. There are large seasonal variations in the response of the surface fluxes, as presented in Sect. 3.2.

The changing wind speed (Fig. 5) is closely related to the perturbations to the surface roughness length, and influences the turbulent heat fluxes. The reduced wind speed in the northern part of the domain contributes to a decrease in the sensible heat flux. An increase in wind speed is seen along the area of mixed forest perturbation.

Figure 6 shows the 10-year average effect of vegetation changes on near-surface atmospheric variables. The $2 \mathrm{~m}$ temperature (left panels) is sensitive to surface fluxes of sensible and latent heat, and to the surface radiative budget. The overall effect on this variable is a good climatic indicator of the 

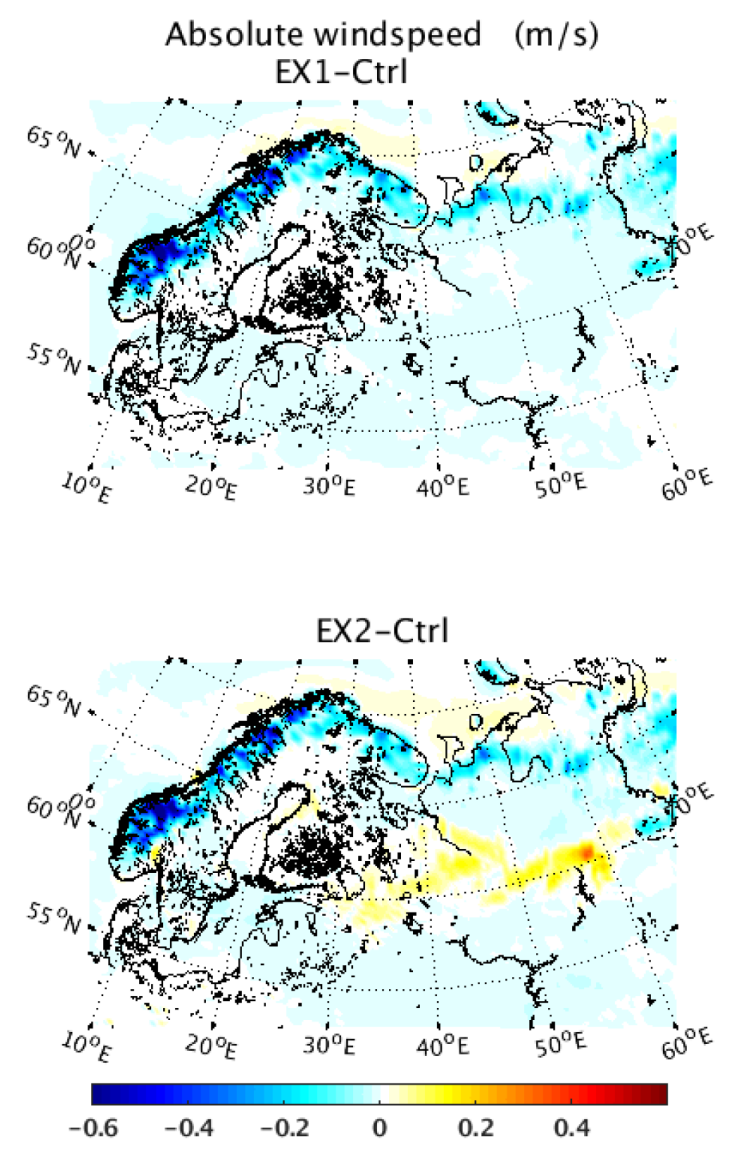

Figure 5. Changes in 10-year average absolute wind speed $\left(\mathrm{m} \mathrm{s}^{-1}\right)$ for Ex 1 (upper panel) and Ex 2 (lower panel) as compared to the control run.

effects of vegetation changes on the atmosphere. In Ex 1, we see the largest effect in the northeastern part of the domain (upper left panel). The areas with the highest increase in temperature are dominated by, although not restricted to, areas with a northward-expanding evergreen needleleaf forest. A temperature increase is also seen along areas of shrub expansion, although with a weaker average response. The 10 -year average increase in $2 \mathrm{~m}$ temperature in these areas (total area of changed vegetation in Ex 1) is $0.11^{\circ} \mathrm{C}$. The weak response in the $2 \mathrm{~m}$ temperature is a result of the compensating effect of the lowered surface albedo by the increase in latent heat flux, yielding small differences in the $2 \mathrm{~m}$ temperature. Additionally, reduced wind speed and decreases in heat transfer to the near-surface atmosphere by sensible heat flux lowers the near-surface temperature response.

In Ex 2 (Fig. 6, lower left panel) the dominant feature is the contrasting cooling effect of the southern border mixed forest northward migration. The annual average effect of this vegetation change is a cooling of $0.19^{\circ} \mathrm{C}$, which together with the northern vegetation shifts results in a total average effect of combined vegetation shifts of $0.0^{\circ} \mathrm{C}$, averaged over all grid cells with vegetation changes. This cooling can be ex- plained by the increase in surface albedo related to this vegetation perturbation, yielding less radiative warming of the surface and corresponding weaker heat transfer by turbulent heat fluxes to the atmosphere. Figure 7 summarizes changes in near-surface atmospheric variables, given as average effects resulting from vegetation changes in Ex 1 (left bars), Ex 2-Ex 1 (middle bars) and all of the vegetation changes, applied in Ex 2 (right bars). Seasonal statistical significance of corresponding variables is presented in Sect. 3.2.

Ten-year average changes in planetary boundary layer height (PBLH) and surface pressure resulting from vegetation changes is shown in Fig. 8. The PBLH increased in the areas with shrub expansion and northward shifts in evergreen needleleaf forest, and decreased in areas with mixed forest northward expansion, reflecting the results for the turbulent heat fluxes and temperature changes. A pattern of increased surface pressure along the northern coastline of the domain is clear, especially over regions of northward-expanding evergreen forest.

Figure 9 shows the 10-year average percentage change in volumetric liquid soil water content for Ex 2 compared to the control run, for each of the four simulated soil layers. As demonstrated by the figure, the vegetation change most influential on the water content is the area of northwardexpanding evergreen forest into previously tundra-covered area in the north of the domain. The change is larger deeper down in the soil, reflecting the fact that the number of root layers for the evergreen forest increases to four, as compared to the tundra, which only influences the three upper layers. The lowering of soil water content is a result of the ability of the evergreen forest to extract more water from the ground compared to tundra vegetation, and is reflected in the increase in the latent heat flux in this area. The other vegetation changes do not significantly affect the soil moisture content. However, the change of evergreen trees into mixed deciduous forest influences the annual cycle of soil moisture content by decreasing it in spring and increasing it in late summer and autumn (Fig. 10).

\subsection{Seasonal averages: when are various effects largest?}

Seasonal variations in surface and near-surface variables as results of the various vegetation changes are presented in Fig. 10. Each stippled line shows 10-year monthly mean changes for one type of vegetation change as averages only cover the grid cells with the corresponding vegetation shift. The overall mean effect of all vegetation changes, averaged over the total area of all vegetation shifts, is shown in the black line marked Ex 2-control. Black circles indicate monthly area means which pass the $95 \%$ confidence interval based on Student's $t$ test. Confidence intervals are computed from the control simulation monthly means for each area with changed vegetation, and circled points as such rep- 

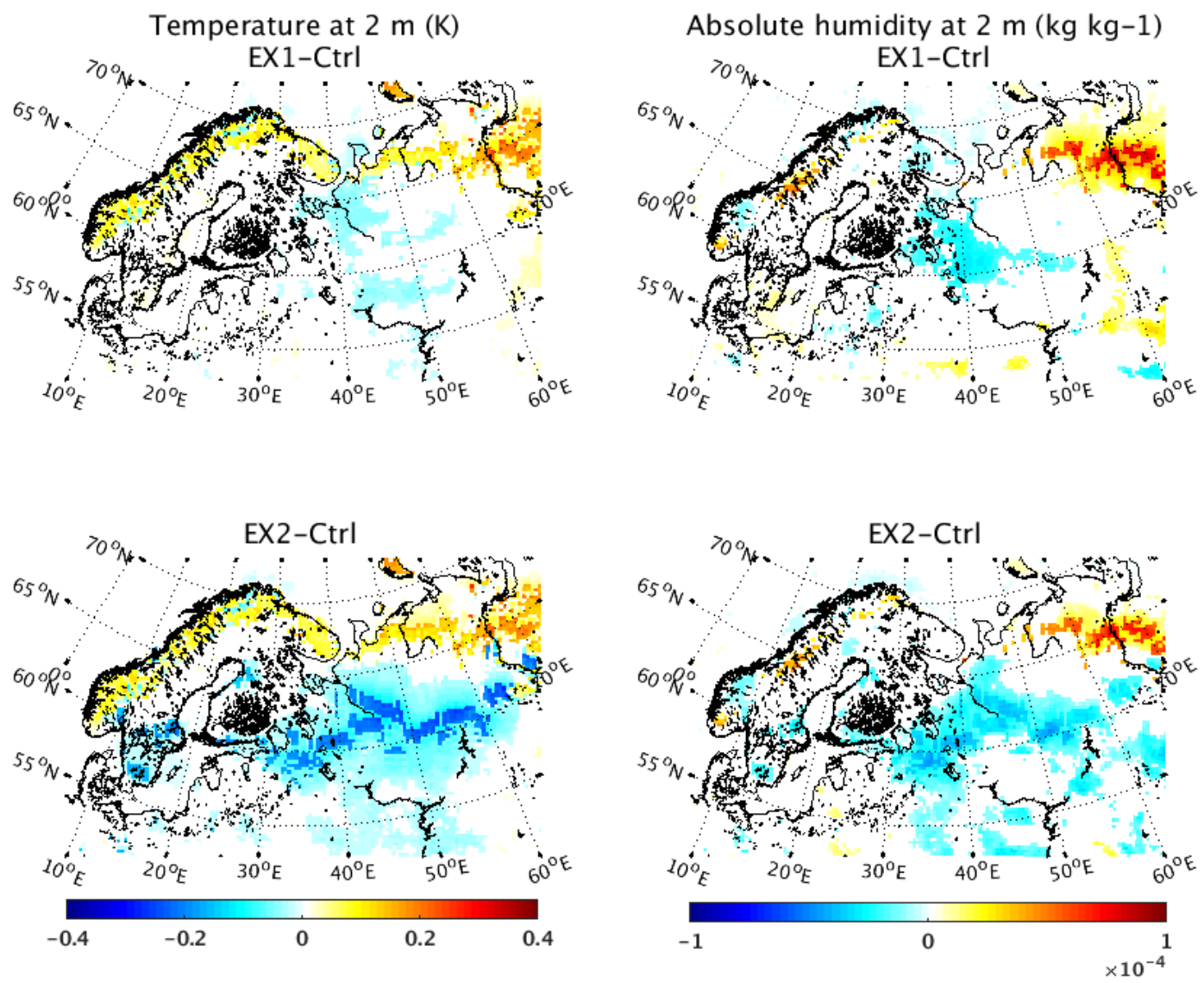

Figure 6. Changes in 10-year average near-surface variables as compared to the control run. Two-meter temperature change (left panels) and change in $2 \mathrm{~m}$ absolute humidity (right panels). Ex 1 in upper panels; Ex 2 in lower panels (only showing significant results at the $95 \%$ confidence level).

resent months where the average values for each area are significantly different from the control simulation area means.

For the albedo (Fig. 10, upper left panel), the increase due to the northward migrating mixed forest is most prominent in the spring and autumn months, whereas the increase is less in the summer and smallest during winter. The contrasting negative effect on the albedo resulting from the evergreen needleleaf tree northward migration is largest in autumn and the mean effect throughout the year is a lowering of the surface albedo. The maximum change in the spring and autumn months reflects the close dependence on the LAI, which varies throughout the year. The effect in the winter months is on average small because of snow covering the vegetation. The spatial variability across the domain is largest in the spring and autumn months (not shown), and smallest in summer, reflecting the fact that LAI changes occur at an uneven rate across the domain in these transitional periods (the changes in albedo and LAI result from changing parameter values and are therefore not statistically tested).

The largest effect on the sensible heat flux (Fig. 10, middle left panel) is seen in areas of evergreen needleleaf forest expansion in summer, on average reducing the heat flux by $11.2 \mathrm{~W} \mathrm{~m}^{-2}$ in July. In winter and autumn, the effect on the sensible heat flux is reversed as result of this vegetation change, increasing the heat flux in these areas, especially in autumn. The shrub expansion only has a weak decreasing effect on the sensible heat flux in summer. The mixed forest migration has a pronounced year-round effect on the sensible heat flux, with the most prominent reduction in the spring and early summer. The overall effect of all vegetation changes (solid line) is close to zero in winter, and a reduction in sensible heat flux to the atmosphere is seen over the summer.

For the latent heat flux (Fig. 10, middle right panel), the effect of the shrub expansion is low, and the two types of forest expansion dominate the results in contrasting ways. The evergreen needleleaf forest expansion causes a sharp increase in summertime latent heat fluxes compared to the control run. Absolute values of the latent heat flux are largest in the summer months, and so are the differences due to vegetation shifts, with a peak increase in July of on average $18 \mathrm{~W} \mathrm{~m}^{-2}$. The mixed forest expansion on the other hand, acts to decrease latent heat fluxes year-round, and the decreasing effect is largest in June with an average reduction of about $10.3 \mathrm{~W} \mathrm{~m}^{-2}$. The net effect is a year-round slight decrease 


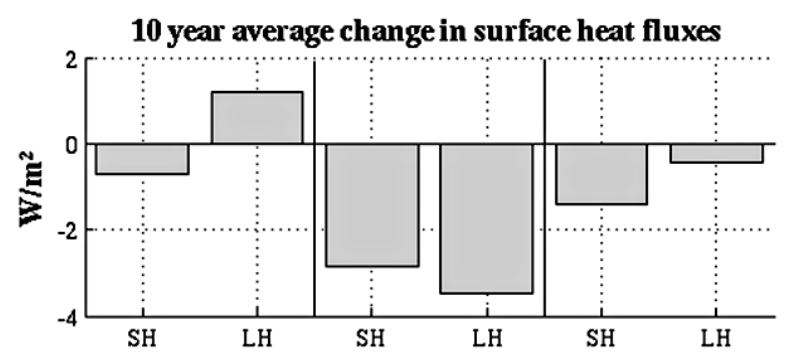

10 year average change in $2 \mathrm{~m}$ temperature

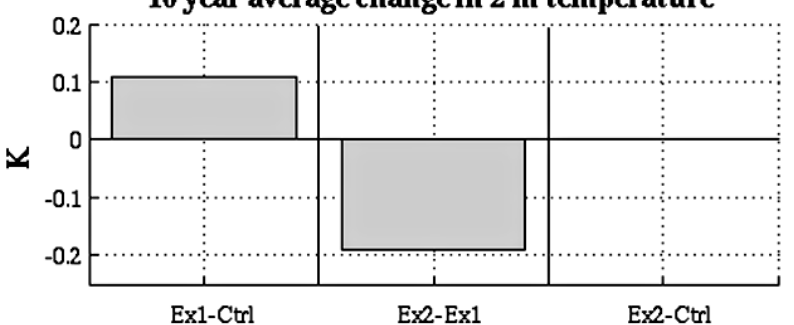

10 year average change in $2 \mathrm{~m}$ humidity

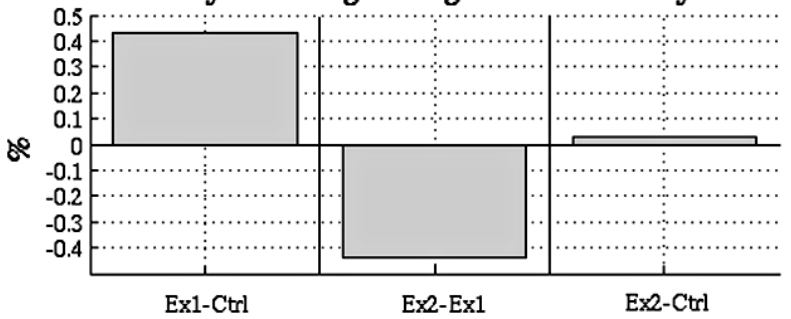

Figure 7. Changes in 10-year averages in surface variables, as averages per area of vegetation change only. Left-side bars show vegetation shift effects of Ex 1 compared to the control run (northward migration of evergreen forest and shrub expansion combined). The middle bars show the effect of mixed forest migration only, given as the difference between Ex 2 and Ex 1. Bars on the right show the effect of all vegetation changes together, averaged over all areas with vegetation changes. Differences in sensible heat flux $(\mathrm{SH})$ and latent heat flux (LH) are shown in the top panel, $2 \mathrm{~m}$ temperature changes in the middle panel, and $2 \mathrm{~m}$ absolute humidity changes in the bottom panel. Note that areas of different vegetation shifts are not equal in size, and therefore averages are not additive.

in latent heat fluxes from the surface to the atmosphere, with largest effect in spring (solid line).

The $2 \mathrm{~m}$ humidity varies on a monthly basis similar to the latent heat flux as these two variables are closely linked. The effect on humidity is dominated by the two types of forest migration, whereas the effect of shrub expansion is small. The evergreen needleleaf forest expansion has a prominent positive effect, increasing the humidity especially in summer, whereas the mixed forest expansion acts to decrease the $2 \mathrm{~m}$ humidity in these areas, having the largest effect over the summer months (not shown). The humidity is dependent on the soil moisture through transpiration and ground evaporation. The soil moisture content is most prominently affected by the conversion of tundra to evergreen forest as the forest subtracts more soil water from all four layers compared to tundra vegetation. As a result of the increased rooting depth, the most prominent effect is on the bottom layer (layer four), as presented in Fig. 10 (lower left panel).

The effects of vegetation changes on the $2 \mathrm{~m}$ temperature are complex and vary across the areas of vegetation shifts and seasons (Fig. 10, lower right panel). However, despite, in part, large effects on surface heat fluxes, the overall $2 \mathrm{~m}$ temperature response is low, and the area mean differences are not statistically significant. In areas with shrub expansion there are small yet persistent year-round positive effects on the temperature compared to the control run, with the largest effects occurring in the autumn and winter months. In areas with evergreen forest expansion we see a wintertime heating, whereas the summertime effect is opposite, causing a cooling of the $2 \mathrm{~m}$ temperature in June through August, reflecting the decrease in sensible heat flux in the same period. The effect of the mixed forest migration is a modest year-round cooling of the $2 \mathrm{~m}$ temperature, and the effect is largest in the spring and autumn months, and lowest in mid-summer. The overall effect is a net increase in $2 \mathrm{~m}$ temperatures in winter, and decreasing $2 \mathrm{~m}$ temperatures in summer (solid line). This is accounting for all vegetation shifts.

\subsection{Conditional effects: under which conditions are effects the largest?}

The latent heat flux is mainly the combined effect of soil evaporation, transpiration and evaporation from interception. The part most closely linked to the specific type of vegetation cover is the evapotranspiration (i.e., transpiration and evaporation of intercepted water), which depends on water availability (either as intercepted water or to the plant through the roots), the efficiency of turbulent transfer and the evaporative power of the ambient atmosphere. As both the number of soil layers available to the plants roots and the LAI, and thereby the rate of evapotranspiration, vary across vegetation types, the dependence of latent heat (and thus the evapotranspiration) on soil moisture, as compared to the vapor pressure deficit (VPD) in the surrounding air, may shift as vegetation category changes. To investigate these effects in more detail, the effects of selected vegetation changes on the relationship between the latent heat flux and soil moisture, and latent heat flux and ambient air vapor pressure deficit are shown in Fig. 11. The effect of shrub expansion on surface heat fluxes is low, and so we focus here on areas with forest migration. As fluxes and flux response to vegetation shifts are largest in the summer months, only monthly averages of the summer season (JJA) are used, and correlation coefficients based on averages in each area are given. Changes averaged over areas with evergreen forest expansion into tundra is shown in the upper panels, and mixed forest northward migration in the lower panels. The white circles indicate monthly mean values as simulated in the control run, and black dots represent monthly mean values averaged over the same area after vegetation shifts. 

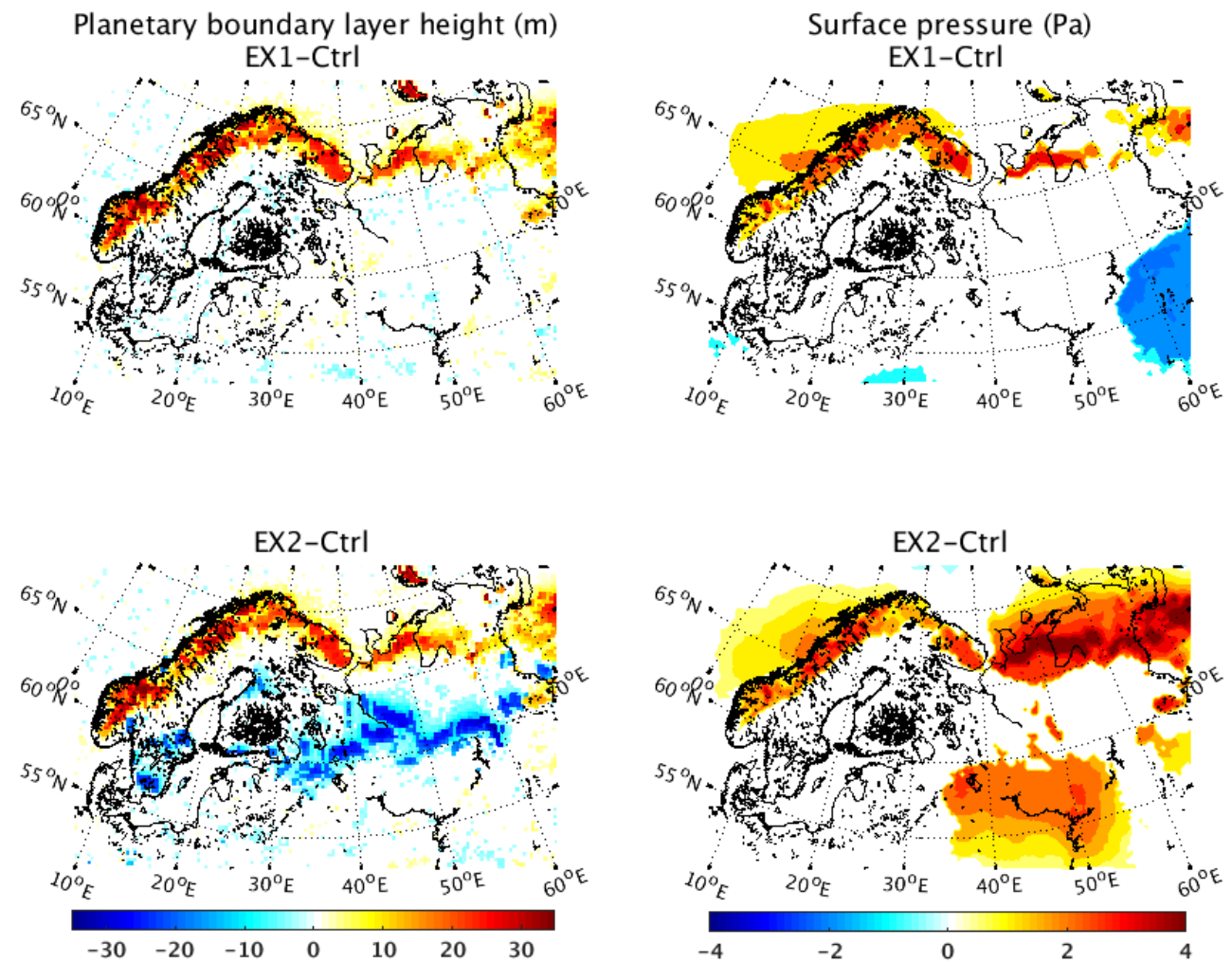

Figure 8. Changes in 10-year average planetary boundary layer height (left panels) and surface pressure (right panels) for Ex 1 (upper panels) and Ex 2 (lower panels) compared to the control run (only showing results significant at the $95 \%$ confidence level).

The correlation coefficient between latent heat flux and soil moisture content is low, regardless of vegetation type. This indicates that the soil moisture content does not limit the rate of latent heat, suggesting that the latent heat flux is limited by the available radiative energy, rather than available water (Seneviratne et al., 2010). The latent heat's correlation to VPD increased from 0.68 to 0.74 when changing vegetation from tundra to evergreen forest, indicating that the evergreen forest latent heat flux is more dependent on the ambient atmosphere than the tundra vegetation it replaces. Additionally, the evergreen forest can reach four root layers rather than three, which is the case for the tundra, making more soil water available. For the mixed forest northward expansion, the same shifts in correlation occurs, indicating that shifting vegetation type from evergreen forest to mixed forest also acts to increase the latent heat flux dependence on VPD rather than soil moisture.

\section{Discussion of results}

Perturbations in this study were limited to changing the dominant land category in given areas, and accordingly to the changes in certain physical properties of the surface. The parameterization of physical processes in the model has not been altered in order to maintain a high relevance to other studies. The modified IGBP MODIS vegetation data set is regarded a suitable basis for perturbations, although many alternatives do exist with regard to data sets, and vegetation perturbations that will influence the results. Liess et al. (2011) used the IGBP MODIS land cover data set in which no alterations were made to the land use category of "open shrub land" as is the case for the modified MODIS data set (where replaced by various tundra vegetation classes). They found the open shrub land use class to be a suitable category for forest conversion across the Arctic and northern boreal domain. This represents a similar but somewhat larger land use change than the ones applied in our study, although in good agreement with observational data and estimates for future changes in the area (Liess et al., 2011). We have not made any assumptions related to the vegetation coverage after changing vegetation type, i.e., the greenness vegetation fraction is left unaltered.

The perturbations applied here represent simplified estimates of future vegetation distribution, based on observed trends in vegetation migration in the area. As such, the results are not possible to validate against time- and site-specific observations. However, some general features resulting from similar vegetation changes, as observed in large-scale, crosssite measurement studies, may help determine whether modeled results are in line with expectations or differ substantially. In the following we relate our results to a few such 

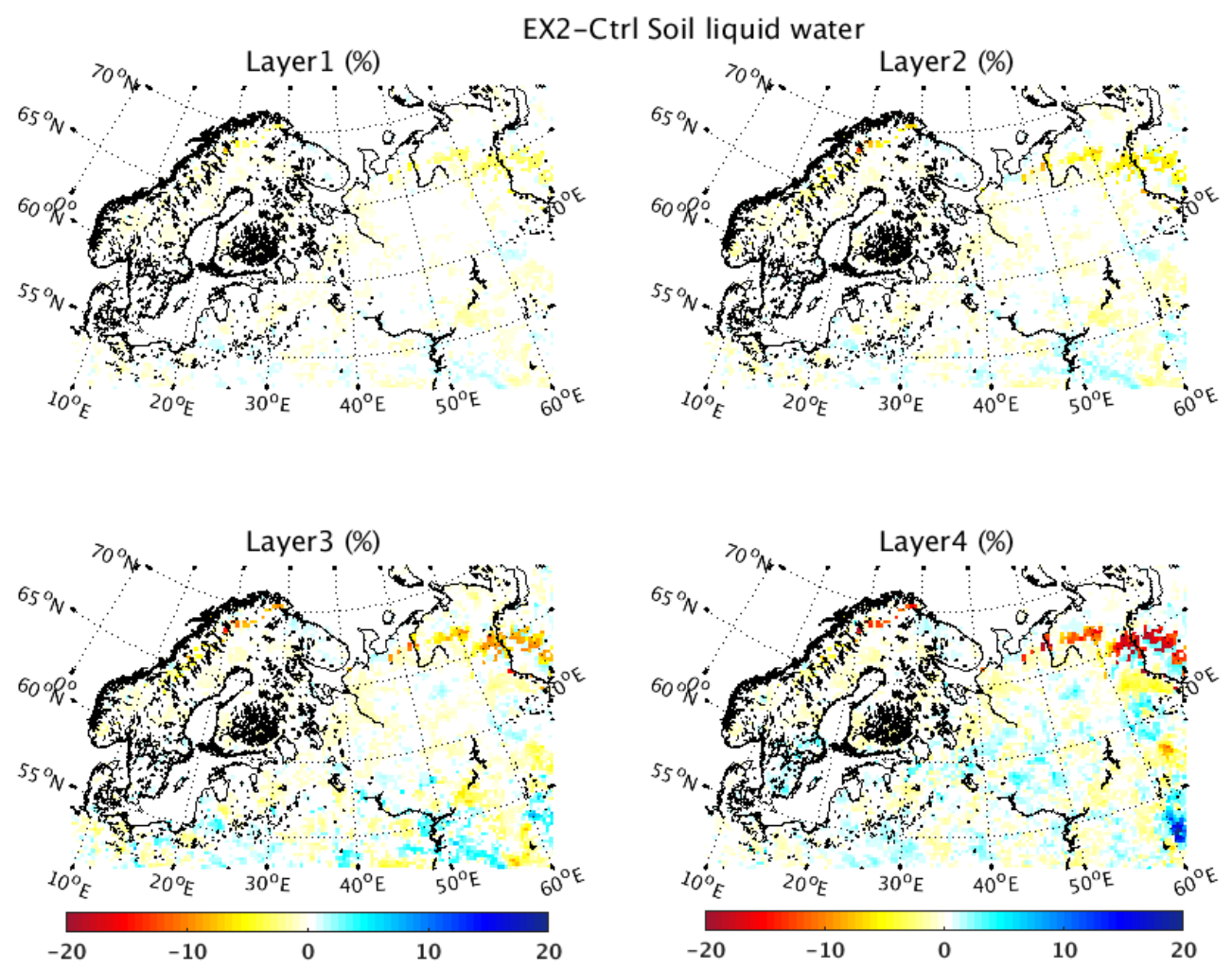

Figure 9. Percentage change in 10-year average volumetric liquid water soil content for each soil layer, as the difference between Ex 2 and the control run. Note that red indicates dryer conditions, and blue wetter conditions as compared to the control run (only showing significant results at the $95 \%$ confidence level).

studies in order to point to possible strengths and weaknesses in model parameterization and configuration.

Changes in albedo are largest in the spring and autumn months, reflecting the differences in LAI in these periods. In summer, the broadleaved deciduous species reach their peak LAI values, and the difference in the evergreen needleleaf tree values is smallest. In winter, the effect of difference in LAI is at its largest; however, its effect on the surface albedo is to a great extent masked by snow cover. The areas of evergreen needleleaf forest expansion have a profound impact on summer and autumn albedo, but interestingly a low impact on modeled albedo during winter months. In fact, the effect of the evergreen forest migration on winter albedo is nearly zero during winter months.

It has been suggested that the lowering of surface albedo over snow-covered ground, as result of taller and more complex canopies as compared to snow-covered tundra, will greatly affect wintertime surface heat fluxes and that the lower wintertime albedo would also increase snowmelt and prolong growing seasons (e.g., Bonan et al., 1992; Betts and Ball, 1997). However, the parameterization of snow albedo in relation to high-latitude vegetation has been pointed out as a source of uncertainty in high-latitude climate modeling (e.g., Qu and Hall, 2006; Loranty et al., 2014). Loranty et al. (2014) found that on average the CMIP5 model tree cover and albedo do not correlate well. They also point out that the observed general decreasing albedo with increasing tree cover south of the latitudinal tree line seems badly represented in coupled climate models.

In WRF (Noah), the vegetation-specific surface albedo is weighted against a corresponding vegetation-specific snow albedo value from Robinson and Kukla (1985). A vegetationdependent threshold value with regard to snow water equivalent (SWE) is used to determine if the ground is fully snowcovered, and for fresh snow, a higher albedo value is estimated to decay towards the fixed vegetation snow albedo values over a period of a few days. This parameterization is based on Koren et al. (1999), after revisions by Livneh et al. (2010). The snow albedo parameterization in WRF Noah has been the subject of a number of studies in recent years, some revealing weaknesses related to early snowmelt as a result of too-low snow albedo values. However, recent improvements were suggested by Wang et al. (2010), who found that an increase in the snow cover threshold value for high vegetation, and lowering for low vegetation reduced over- (under-) estimation of snow albedo over high (low) vegetation. This alteration, together with other minor improvements, has recently been made available as an option in Noah and Noah MP (Noah LSM with multi-parameterization options) (Yang et al., 2011; Niu et al., 2011), and as such it 

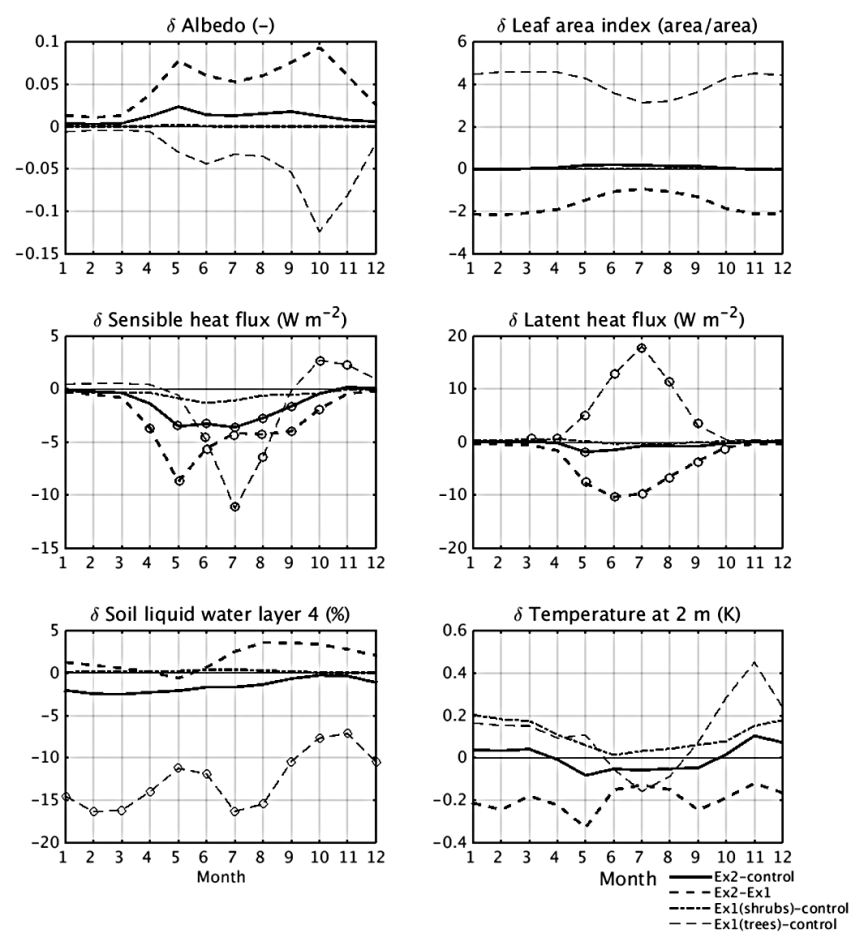

Figure 10. Seasonal changes in 10-year monthly average surface and near-surface variables for each area with changed vegetation. Average of all vegetation changes shown by the thick black line (Ex 2-control), black circles indicate significant results at the $95 \%$ confidence level.

would be of interest to test this version in a further study. A verification of estimated snow cover and snow albedo against observations for the simulated study area is beyond the focus of this study; however, the results herein suggest that the rather low wintertime warming seen in the evergreen forest expanding areas may be somewhat underestimated.

Beringer et al. (2005) examined the potential influence of structural vegetation changes by measuring surface energy exchanges along tundra to forest transition zone in Alaska during the summer of 1999 . They measured sensible heat fluxes and evapotranspiration at five different sites (tundra, low shrub, tall shrub, woodland and forest) acting as an analogue to vegetation transitions that might occur under enhanced warming. Despite the fact that measurement sites in Beringer et al. (2005) and the simulation domain herein differ in both time and continent, comparing the results points to some general features of summer surface energy partitioning related to vegetation changes, and may as such be useful. They reported that small differences in latent energy flux between the sites, and a decrease in ground evaporation, were compensated by an increase in evapotranspiration moving from tundra towards more complex canopies. Sensible heat flux was increased going from tundra to more complex canopy vegetation, with both shrubs and trees enhancing the sensible heat flux to the atmosphere. These findings are sup- ported by modeled findings for heat flux changes resulting from similar vegetation changes (Jeong et al., 2011, 2014; Snyder and Liess, 2014). Snyder and Liess (2014) found annual mean increases in both sensible and latent heat fluxes as responses to lowered albedo and increased net radiative forcing. For the summer months, the increased radiative flux was partitioned into sensible rather than latent heat, due to repartitioning of evaporative flux, leading to a JJA temperature increase of $0.4 \mathrm{~K}$, and little or no increase in nearsurface humidity and precipitation. Jeong et al. (2014) on the other hand, found increases in both latent and sensible summer season fluxes in response to Arctic greening, leading to relatively large increases in JJA near-surface temperatures $(1.95 \mathrm{~K})$.

These results stand in contrast to our simulated sensible heat flux, which is reduced in summertime as result of tree and shrub expansion into previously tundra-covered regions. In areas with changing tundra (from mixed tundra to wooded tundra), the largest monthly mean effect is seen in June, with an average reduction of sensible heat of $1.3 \mathrm{~W} \mathrm{~m}^{-2}$, and in areas with northward-expanding evergreen forest the main effect is seen in July, with a mean reduction of the sensible heat flux by $11.2 \mathrm{~W} \mathrm{~m}^{-2}$. The simulated sensible heat flux is closely related to wind speed, and in areas where wind speeds are lowered, the turbulent heat fluxes decrease. Furthermore, the increase in available soil moisture (by increased rooting layers) going from tundra to evergreen forest acts to increase the transpiration and thereby the latent heat flux. Additionally, increased leaf area and corresponding inception and canopy evaporation serves to increase the latent heat flux and near-surface humidity, resulting in increased summer precipitation. An analysis of the mean JJA rainfall in this area alone shows an increase in accumulated rainfall of $3.35 \%$ over the ten summers. Increased rainfall would further increase the partitioning of increased absorbed radiation into latent rather than sensible heat flux, and thereby decrease heating of the overlying atmosphere. This flux repartitioning leads to an annual $2 \mathrm{~m}$ temperature increase of $0.12 \mathrm{~K}$ in areas with evergreen forest expansion.

The specifics of vegetation perturbations applied here might have influenced these results. Here, we have chosen to only perturb the vegetation type in each area. The greenness fraction is not altered, which influences the evapotranspiration and thereby available energy for sensible heat, as demonstrated by (Hong et al., 2009). Here, we considered this approach sufficient, as the greenness fraction acts to scale the LAI (and other vegetation parameters) values within the vegetation specific range (as indicated in the plotted results for the variable), applying the new vegetation category to new areas would not imply a scaling of the LAI to values outside the respective category's assigned range. Further investigation of the sensitivity of these parameters is beyond the scope of this study, but is certainly an important subject for further work.

Based on a broad analysis of available observational data from Arctic and boreal ecosystems, Eugster et al. (2000) 

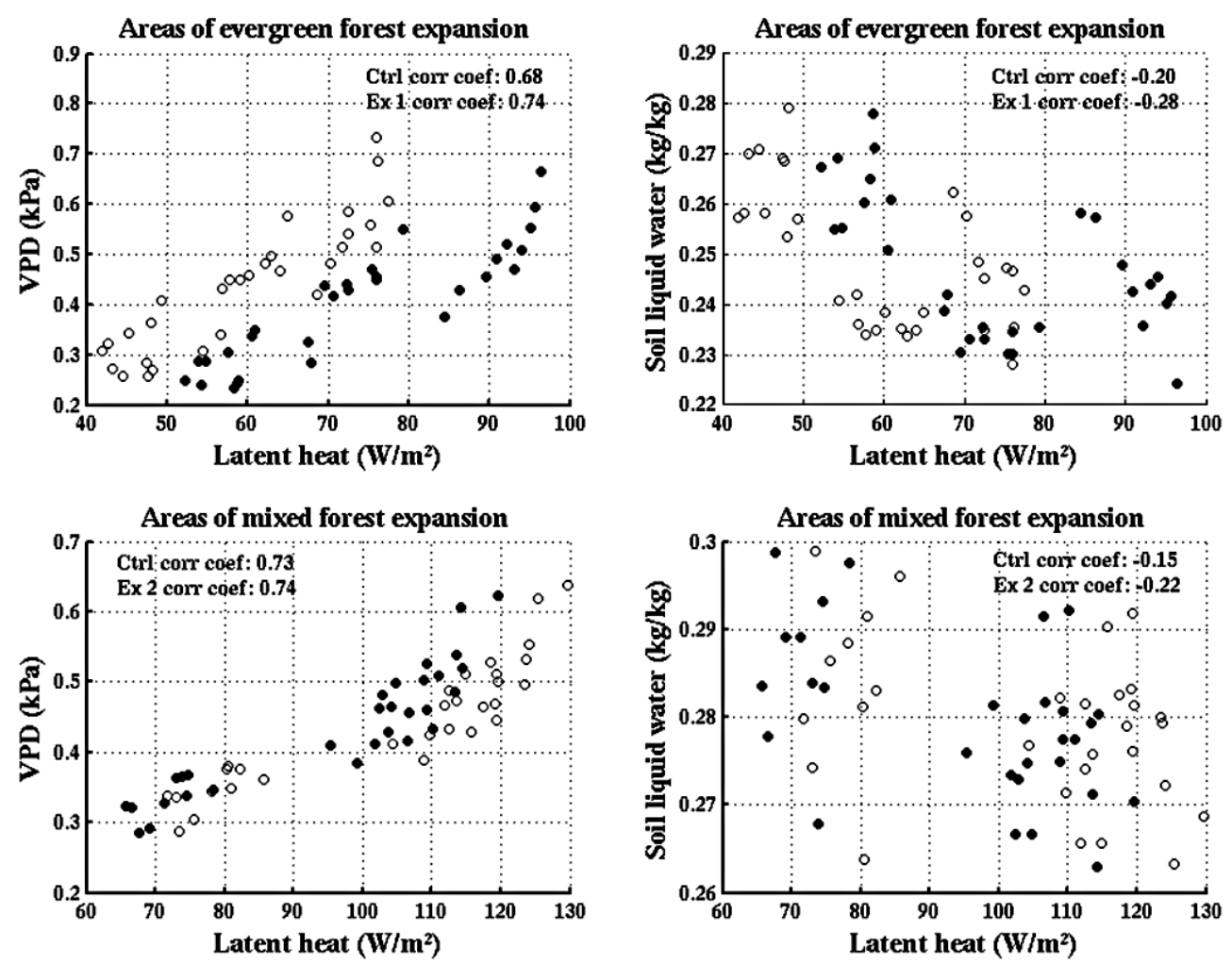

Figure 11. Effect of change in vegetation cover on the relationship between the monthly mean latent heat flux and VPD at $2 \mathrm{~m}$ (left panels), and latent heat and liquid soil moisture content in the top soil layer (right panels). The data are based on summer season (JJA) monthly means, averaged over areas with northward-expanding evergreen forest (upper panels) and areas with northward migrating mixed forest (bottom panels).

found a general increase in latent heat flux in areas with deciduous trees replacing evergreen needleleaf forest, due to lower canopy conductance in conifer trees. A similar yet less drastic replacement was made in our Ex 2, where replacement of evergreen needleleaf forest by mixed forest (representing a mix of conifer and deciduous trees). This shift in vegetation causes a modeled year-round reduction in latent heat. This is a result of the model parameterization, which causes a decrease in LAI, but no increase in stomatal conductance given the vegetation shift in Ex 2, and thereby acts to decrease the latent heat release to the atmosphere. Our experiments suggest a significant increase in latent heat flux in the summer months in areas with evergreen forest expansion.

Based on summer season observations of flux partitioning over 66 site years within the FLUXNET project (Baldocchi et al., 2001), Wilson et al. (2002) found that deciduous forest sites in general had a lower summer Bowen ratio $(\sim 0.25$ $0.5)$ than conifer forest sites $(\sim 0.5-1.0)$, which again were slightly lower than tundra Bowen ratios. In our simulations, areas with a northward migrating evergreen forest (northern border) reduce the summer season (JJA) Bowen ratio by a factor of 2, going from wooded tundra to evergreen forest. In areas of northward migrating mixed forest (southern boarder), the decrease in both sensible and latent heat fluxes results in a slightly decreasing Bowen ratio from 0.51 to 0.49 .

The modeled increase in evapotranspiration in areas of northward migrating evergreen forest also affect the soil moisture, with more water being extracted from the deeper layers of soil in particular, owing to the increased number of available soil layers to the evergreen forest. However, the latent heat flux is not highly correlated to the soil moisture content in this domain as fluxes are largely energy limited rather than moisture limited. Shifting the vegetation type towards higher LAI vegetation acts to reduce correlations for summer months between latent heat and soil moisture, and increase correlations with VPD. These results are in agreement with the findings of Kasurinen et al. (2014), who measured latent heat fluxes over a total 65 different boreal and Arctic sites. They found a general increase in latent heat release and a higher correlation to VPD in observations from forested boreal sites compared to tundra ecosystems.

\section{Concluding remarks}

In this study, observed trends of boreal forest migration were represented by applying perturbations to the current boreal 
vegetation distribution in two separate experiments. The perturbations were simple enough to extract their separate effects on the overlying atmosphere, and moderate enough that they induce realistic and relevant information on atmospheric response to vegetation structural changes.

The atmospheric response resulting from the vegetation changes made in Ex 1 and Ex 2 largely points in different directions. The Ex 1 high north shrub and evergreen forest expansion largely leads to a decreasing albedo and larger latent heat fluxes, which subsequently lead to enhanced nearsurface temperatures and deeper and wetter planetary boundary layer. Increased summer precipitation and reduced wind speed leads to lower sensible heat flux, causing a lowering of the Bowen ratio changing from tundra to conifer forest. On the other hand, the Ex 2 replacement of evergreen forest by more broadleaved species along the southern border of the boreal forest leads to lower LAI, higher albedo and lower surface fluxes, resulting in lower heating of the boundary layer and lower near-surface temperatures and humidity. The differing response of the various vegetation changes results in that the overall effect on the domain is a near-zero temperature response over a 10-year average. However, there are large seasonal differences in atmospheric response for the individual vegetation shifts.

The study has been successful in uncovering some special features of model parameterization that might yield unexpected results relative to physical observations of vegetation change such as the masking of albedo changes by snow cover, reducing the expected warming in winter and spring, and the lowering (instead of raising) of sensible heat for more complex canopies. Although latent heat and soil moisture content are closely linked variables, the low correlations found between the two prove that the high-latitude study domain is energy limited rather than water limited throughout the year.

In our simulations, the perturbations are kept moderate enough to be achieved within this century, and although it is a result of large climatic average changes in the area, the mean response of the present-day atmosphere is not regarded very differently from what can be expected as feedbacks from the one accompanying such vegetation changes. We have mainly focused on long-term average effects and seasonal mean variations. Many feedback processes are not possible to study in this time resolution, and shorter, more specific time periods might be advantageous in this respect. For the purpose of more detailed investigation on finer temporal and spatial scales, future work should include the use of these long-term simulations as a framework for nested, finer-resolution simulations, focusing on more specific processes in vegetationatmosphere feedbacks.

Acknowledgements. We would like to express our gratitude to Benjamin Alexander Laken for help with the statistical analysis and other improvements to the manuscript. Additionally, we would like to thank the three anonymous referees for their constructive comments and suggestions.

Edited by: P. Stoy

\section{References}

Alo, C. A. and Wang, G.: Potential future changes of the terrestrial ecosystem based on climate projections by eight general circulation models, J. Geophys. Res.-Biogeo., 113, G01004, doi:10.1029/2007JG000528, 2008.

Arora, V. K. and Montenegro, A.: Small temperature benefits provided by realistic afforestation efforts, Nat. Geosci., 4, 514-518, 2011.

Baldocchi, D., Kelliher, F. M., Black, T. A., and Jarvis, P.: Climate and vegetation controls on boreal zone energy exchange, Glob. Change Biol., 6, 69-83, 2000.

Baldocchi, D., Falge, E., Gu, L., Olson, R., Hollinger, D., Running, S., Anthoni, P., Bernhofer, C., Davis, K., Evans, R., Fuentes, J., Goldstein, A., Katul, G., Law, B., Lee, X., Malhi, Y., Meyers, T., Munger, W., Oechel, W., Paw, K. T., Pilegaard, K., Schmid, H. P., Valentini, R., Verma, S., Vesala, T., Wilson, K., and Wofsy, S.: FLUXNET: A New Tool to Study the Temporal and Spatial Variability of Ecosystem - Scale Carbon Dioxide, Water Vapor, and Energy Flux Densities, B. Am. Meteorol. Soc., 82, 24152434, 2001.

Beringer, J., Tapper, N. J., McHugh, I., Chapin, F. S., Lynch, A. H., Serreze, M. C., and Slater, A.: Impact of Arctic treeline on synoptic climate, Geophys. Res. Lett., 28, 4247-4250, 2001.

Beringer, J., Chapin Iii, F. S., Thompson, C. C., and McGuire, A. D.: Surface energy exchanges along a tundra-forest transition and feedbacks to climate, Agr. Forest. Meteorol., 131, 143-161, 2005.

Betts, A. K., and Ball, J. H.: Albedo over the boreal forest, J. Geophys. Res.-Atmos., 102, 28901-28909, 1997.

Betts, R. A., Falloon, P. D., Goldewijk, K. K., and Ramankutty, N.: Biogeophysical effects of land use on climate: Model simulations of radiative forcing and large-scale temperature change, Agr. Forest. Meteorol., 142, 216-233, 2007.

Bhatt, U. S., Walker, D. A., Raynolds, M. K., Comiso, J. C., Epstein, H. E., Jia, G., Gens, R., Pinzon, J. E., Tucker, C. J., Tweedie, C. E., and Webber, P. J.: Circumpolar Arctic Tundra Vegetation Change Is Linked to Sea Ice Decline, Earth Interact., 14, 1-20, 2010.

Bonan, G. B.: Forests and climate change: Forcings, feedbacks, and the climate benefits of forests, Science, 320, 1444-1449, 2008.

Bonan, G. B., Pollard, D., and Thompson, S. L.: Effects of boreal forest vegetation on global climate, Nature, 359, 716-718, 1992.

Chapin, F. S., Sturm, M., Serreze, M. C., McFadden, J. P., Key, J. R., Lloyd, A. H., McGuire, A. D., Rupp, T. S., Lynch, A. H., Schimel, J. P., Beringer, J., Chapman, W. L., Epstein, H. E., Euskirchen, E. S., Hinzman, L. D., Jia, G., Ping, C. L., Tape, K. D., Thompson, C. D. C., Walker, D. A., and Welker, J. M.: Role of land-surface changes in Arctic summer warming, Science, 310, 657-660, 2005.

Chapin, F. S., McGuire, A. D., Ruess, R. W., Hollingsworth, T. N., Mack, M. C., Johnstone, J. F., Kasischke, E. S., Euskirchen, E. S., Jones, J. B., Jorgenson, M. T., Kielland, K., Kofinas, G. P., Turet- 
sky, M. R., Yarie, J., Lloyd, A. H., and Taylor, D. L.: Resilience of Alaska's boreal forest to climatic change, Can. J. Forest. Res., 40, 1360-1370, 2010.

Chen, I.-C., Hill, J. K., Ohlemüller, R., Roy, D. B., and Thomas, C. D.: Rapid Range Shifts of Species Associated with High Levels of Climate Warming, Science, 333, 1024-1026, 2011.

Eugster, W., Rouse, W. R., Pielke, R. A., McFadden, J. P., Baldocchi, D. D., Kittel, T. G. F., Chapin, F. S., Liston, G. E., Vidale, P. L., Vaganov, E., and Chambers, S.: Land-atmosphere energy exchange in Arctic tundra and boreal forest: available data and feedbacks to climate, Glob. Change Biol., 6, 84-115, 2000.

Friedl, M. A., Sulla-Menashe, D., Tan, B., Schneider, A., Ramankutty, N., Sibley, A., and Huang, X.: MODIS Collection 5 global land cover: Algorithm refinements and characterization of new datasets, Remote Sens. Environ., 114, 168-182, 2010.

Friedlingstein, P., Meinshausen, M., Arora, V. K., Jones, C. D., Anav, A., Liddicoat, S. K., and Knutti, R.: Uncertainties in CMIP5 Climate Projections due to Carbon Cycle Feedbacks, J. Climate, 27, 511-526, 2013.

Hines, K. M., Bromwich, D. H., Bai, L. S., Barlage, M., and Slater, A. G.: Development and Testing of Polar WRF. Part III: Arctic Land, J. Climate, 24, 26-48, 2011.

Hong, S. B., Lakshmi, V., Small, E. E., Chen, F., Tewari, M., and Manning, K. W.: Effects of vegetation and soil moisture on the simulated land surface processes from the coupled WRF/Noah model, J. Geophys. Res.-Atmos., 114, D18118 doi:10.1029/2008jd011249, 2009.

Iacono, M. J., Delamere, J. S., Mlawer, E. J., Shephard, M. W., Clough, S. A., and Collins, W. D.: Radiative forcing by long-lived greenhouse gases: Calculations with the AER radiative transfer models, J. Geophys. Res.-Atmos., 113, D13103, doi:10.1029/2008JD009944, 2008.

Janjić, Z. I.: The Step-Mountain Eta Coordinate Model: Further Developments of the Convection, Viscous Sublayer, and Turbulence Closure Schemes, Mon. Weather Rev., 122, 927-945, 1994.

Jeong, J. H., Kug, J. S., Linderholm, H. W., Chen, D. L., Kim, B. M., and Jun, S. Y.: Intensified Arctic warming under greenhouse warming by vegetation-atmosphere-sea ice interaction, Environ. Res. Lett., 9, 094007 doi:10.1088/1748-9326/9/9/094007, 2014.

Jeong, S. J., Ho, C. H., Park, T. W., Kim, J., and Levis, S.: Impact of vegetation feedback on the temperature and its diurnal range over the Northern Hemisphere during summer in a $2 \times \mathrm{CO}_{2}$ climate, Clim. Dynam., 37, 821-833, 2011.

Kain, J. S.: The Kain-Fritsch Convective Parameterization: An Update, J. Appl. Meteorol., 43, 170-181, 2004.

Kasurinen, V., Alfredsen, K., Kolari, P., Mammarella, I., Alekseychik, P., Rinne, J., Vesala, T., Bernier, P., Boike, J., Langer, M., Belelli Marchesini, L., van Huissteden, K., Dolman, H., Sachs, T., Ohta, T., Varlagin, A., Rocha, A., Arain, A., Oechel, W., Lund, M., Grelle, A., Lindroth, A., Black, A., Aurela, M., Laurila, T., Lohila, A., and Berninger, F.: Latent heat exchange in the boreal and arctic biomes, Glob. Change Biol., 20, 3439-3456, doi:10.1111/gcb.12640, 2014.

Koren, V., Schaake, J., Mitchell, K., Duan, Q. Y., Chen, F., and Baker, J. M.: A parameterization of snowpack and frozen ground intended for NCEP weather and climate models, J. Geophys. Res.-Atmos., 104, 19569-19585, 1999.
Liess, S., Snyder, P. K., and Harding, K. J.: The effects of boreal expansion on the summer Arctic frontal zone, Clim. Dyn., 38, 1805-1827, doi:10.1007/s00382-011-1064-7, 2011.

Livneh, B., Xia, Y., Mitchell, K. E., Ek, M. B., and Lettenmaier, D. P.: Noah LSM Snow Model Diagnostics and Enhancements, J. Hydrometeorol., 11, 721-738, 2010.

Lloyd, A. H. and Bunn, A. G.: Responses of the circumpolar boreal forest to 20th century climate variability, Environ. Res. Lett., 2, 045013, doi:10.1088/1748-9326/2/4/045013, 2007.

Loranty, M. M., Berner, L. T., Goetz, S. J., Jin, Y. F., and Randerson, J. T.: Vegetation controls on northern high latitude snowalbedo feedback: observations and CMIP5 model simulations, Glob. Change Biol., 20, 594-606, 2014.

Lucht, W., Schaphoff, S., Erbrecht, T., Heyder, U., and Cramer, W.: Terrestrial vegetation redistribution and carbon balance under climate change, Carbon Balance Manageme., 1, 1-6, 2006.

Mckenney, D. W., Pedlar, J. H., Lawrence, K., Campbell, K., and Hutchinson, M. F.: Potential impacts of climate change on the distribution of North American trees, Bioscience, 57, 939-948, 2007.

Morrison, H., Thompson, G., and Tatarskii, V.: Impact of Cloud Microphysics on the Development of Trailing Stratiform Precipitation in a Simulated Squall Line: Comparison of One- and TwoMoment Schemes, Mon. Weather Rev., 137, 99-1007, 2009.

Myneni, R. B., Keeling, C. D., Tucker, C. J., Asrar, G., and Nemani, R. R.: Increased plant growth in the northern high latitudes from 1981 to 1991, Nature, 386, 698-702, 1997.

Niu, G.-Y., Yang, Z.-L., Mitchell, K. E., Chen, F., Ek, M. B., Barlage, M., Kumar, A., Manning, K., Niyogi, D., Rosero, E., Tewari, M., and Xia, Y.: The community Noah land surface model with multiparameterization options (Noah-MP): 1. Model description and evaluation with localscale measurements, J. Geophys. Res.-Atmos., 116, D12109, doi:10.1029/2010JD015139, 2011.

Overpeck, J., Hughen, K., Hardy, D., Bradley, R., Case, R., Douglas, M., Finney, B., Gajewski, K., Jacoby, G., Jennings, A., Lamoureux, S., Lasca, A., MacDonald, G., Moore, J., Retelle, M., Smith, S., Wolfe, A., and Zielinski, G.: Arctic environmental change of the last four centuries, Science, 278, 1251-1256, 1997.

Parmesan, C. and Yohe, G.: A globally coherent fingerprint of climate change impacts across natural systems, Nature, 421, 37-42, 2003.

Piao, S., Wang, X., Ciais, P., Zhu, B., Wang, T. A. O., and Liu, J. I. E.: Changes in satellite-derived vegetation growth trend in temperate and boreal Eurasia from 1982 to 2006, Glob. Change Biol., 17, 3228-3239, 2011.

Pielke, R. A. and Vidale, P. L.: The boreal forest and the polar front, J. Geophys. Res.-Atmos., 100, 25755-25758, 1995.

Qu, X. and Hall, A.: Assessing Snow Albedo Feedback in Simulated Climate Change, J. Climate, 19, 2617-2630, 2006.

Rietkerk, M., Brovkin, V., van Bodegom, P. M., Claussen, M., Dekker, S. C., Dijkstra, H. A., Goryachkin, S. V., Kabat, P., van Nes, E. H., Neutel, A. M., Nicholson, S. E., Nobre, C., Petoukhov, V., Provenzale, A., Scheffer, M., and Seneviratne, S. I.: Local ecosystem feedbacks and critical transitions in the climate, Ecol. Complex., 8, 223-228, 2011.

Robinson, D. A. and Kukla, G.: Maximum Surface Albedo of Seasonally Snow-Covered Lands in the Northern Hemisphere, J. Clim. Appl. Meteorol., 24, 402-411, 1985. 
Seneviratne, S. I., Corti, T., Davin, E. L., Hirschi, M., Jaeger, E. B., Lehner, I., Orlowsky, B., and Teuling, A. J.: Investigating soil moisture-climate interactions in a changing climate: A review, Earth-Sci. Rev., 99, 125-161, 2010.

Serreze, M. C. and Barry, R. G.: Processes and impacts of Arctic amplification: A research synthesis, Global Planet. Change, 77, 85-96, 2011.

Sitch, S., Huntingford, C., Gedney, N., Levy, P. E., Lomas, M., Piao, S. L., Betts, R., Ciais, P., Cox, P., Friedlingstein, P., Jones, C. D., Prentice, I. C., and Woodward, F. I.: Evaluation of the terrestrial carbon cycle, future plant geography and climate-carbon cycle feedbacks using five Dynamic Global Vegetation Models (DGVMs), Glob. Change Biol., 14, 2015-2039, 2008.

Skamarock, W. C. and Klemp, J. B.: A time-split nonhydrostatic atmospheric model for weather research and forecasting applications, J. Comput. Phys., 227, 3465-3485, 2008.

Skamarock, W. C., Klemp, J. B., Dudhia, J., Gill, D. O., Barker, D. M., Duda, M. G., Huang, X.-Y., Wang, W., and Powers, J. G.: A Description of the Advanced Research WRF Version 3, National Center for Atmospheric Research, Boulder, Colorado, USA, 2008.

Snyder, P. K. and Liess, S.: The simulated atmospheric response to expansion of the Arctic boreal forest biome, Clim. Dynam., 42, 487-503, 2014.

Soja, A. J., Tchebakova, N. M., French, N. H. F., Flannigan, M. D., Shugart, H. H., Stocks, B. J., Sukhinin, A. I., Parfenova, E. I., Chapin, F. S., and Stackhouse, P. W.: Climate-induced boreal forest change: Predictions versus current observations, Global Planet. Change, 56, 274-296, 2007.

Strengers, B. J., Muller, C., Schaeffer, M., Haarsma, R. J., Severijns, C., Gerten, D., Schaphoff, S., van den Houdt, R., and Oostenrijk, R.: Assessing 20th century climate-vegetation feedbacks of landuse change and natural vegetation dynamics in a fully coupled vegetation-climate model, Int. J. Climatol., 30, 2055-2065, 2010.

Sturm, M., McFadden, J. P., Liston, G. E., Chapin, F. S., Racine, C. H., and Holmgren, J.: Snow-shrub interactions in Arctic tundra: A hypothesis with climatic implications, J. Climate, 14, 336344,2001
Tewari, M., Chen, F., Wang, W., Dudhia, J., LeMone, M. A., Mitchell, K., Ek, M., Gayno, G., Wegiel, J., and Cuenca, R. H.: Implementation and verification of the unified NOAH land surface model in the WRF model, 20th conference on weather analysis and forecasting/16th conference on numerical weather prediction, 2004.

Thompson, C., Beringer, J., Chapin, F. S., and McGuire, A. D.: Structural complexity and land-surface energy exchange along a gradient from arctic tundra to boreal forest, J. Veg. Sci., 15, 397-406, 2004.

Wang, Z., Zeng, X., and Decker, M.: Improving snow processes in the Noah land model, J. Geophys. Res.-Atmos., 115, D20108, doi:10.1029/2009JD013761, 2010.

Wilson, K. B., Baldocchi, D. D., Aubinet, M., Berbigier, P., Bernhofer, C., Dolman, H., Falge, E., Field, C., Goldstein, A., Granier, A., Grelle, A., Halldor, T., Hollinger, D., Katul, G., Law, B. E., Lindroth, A., Meyers, T., Moncrieff, J., Monson, R., Oechel, W., Tenhunen, J., Valentini, R., Verma, S., Vesala, T., and Wofsy, S.: Energy partitioning between latent and sensible heat flux during the warm season at FLUXNET sites, Water Resour. Res., 38, 1294, doi:10.1029/2001WR000989, 2002.

Xu, L., Myneni, R. B., Chapin Iii, F. S., Callaghan, T. V., Pinzon, J. E., Tucker, C. J., Zhu, Z., Bi, J., Ciais, P., Tommervik, H., Euskirchen, E. S., Forbes, B. C., Piao, S. L., Anderson, B. T., Ganguly, S., Nemani, R. R., Goetz, S. J., Beck, P. S. A., Bunn, A. G., Cao, C., and Stroeve, J. C.: Temperature and vegetation seasonality diminishment over northern lands, Nature Clim. Change, 3, 581-586, 2013.

Yang, Z. L., Dai, Y., Dickinson, R. E., and Shuttleworth, W. J.: Sensitivity of ground heat flux to vegetation cover fraction and leaf area index, J. Geophys. Res.-Atmos., 104, 19505-19514, 1999.

Yang, Z.-L., Niu, G.-Y., Mitchell, K. E., Chen, F., Ek, M. B., Barlage, M., Longuevergne, L., Manning, K., Niyogi, D., Tewari, M., and Xia, Y.: The community Noah land surface model with multiparameterization options (Noah-MP): 2. Evaluation over global river basins, J. Geophys. Res.-Atmos., 116, D12110, doi:10.1029/2010JD015140, 2011. 